\title{
Biomechanical analysis of reduction technique for lumbar spondylolisthesis: anterior lever versus posterior lever reduction method
}

\author{
Yu-Tsung Lin ${ }^{1 \dagger}$, Kuo-Chih Su ${ }^{2,3,4 \dagger}$, Kun-Hui Chen ${ }^{1,5,6}$, Chien-Chou Pan ${ }^{1,7}$, Cheng-Min Shih ${ }^{1,6,8}$ and \\ Cheng-Hung Lee ${ }^{1,6,9^{*}}$
}

\begin{abstract}
Background: Reduction of lumbar spondylolisthesis during spinal fusion surgery is important for improving the fusion rate and restoring the sagittal alignment. Despite the variety of reduction methods, the fundamental mechanics of lumbar spondylolisthesis reduction remain unclear. This study aimed to investigate the biomechanical behavior while performing spondylolisthesis reduction with the anterior and posterior lever reduction method.

Methods: We developed an L4-L5 spondylolisthesis model using sawbones. Two spine surgeons performed the simulated reduction with a customized Cobb elevator. The following data were collected: the torque and angular motion of Cobb, displacement of vertebral bodies, change of lordotic angle between $L 4$ and $L 5$, total axial force and torque applied on the model, and force received by adjacent disc.

Results: Less torque value $(116 \mathrm{~N}-\mathrm{cm}$ vs. $155 \mathrm{~N}-\mathrm{cm})$ and greater angular motion $\left(53^{\circ} \mathrm{vs} .38^{\circ}\right)$ of Cobb elevator were observed in anterior lever reduction. Moreover, the total axial force received by the entire model was greater in the posterior lever method than that in the anterior lever method $(40.8 \mathrm{~N}$ vs. $16.38 \mathrm{~N})$. Besides, the displacement of both vertebral bodies was greater in the anterior lever method.

Conclusions: The anterior lever reduction is a more effort-saving method than the posterior lever reduction method. The existing evidence supports the biomechanical advantage of the anterior reduction method, which might be one of the contributing factors to successfully treating high-grade lumbar spondylolisthesis with short-segment instrumentation.
\end{abstract}

Keywords: Anterior lever reduction, Posterior lever reduction, Lumbar spondylolisthesis, Biomechanical study

\section{Background}

Lumbar spondylolisthesis is characterized by the forward slippage of one vertebra over the one beneath it. Surgical intervention is generally recommended for patients with high-grade spondylolisthesis after the failure of conservative treatment [1]. The mainstay of surgery for

\footnotetext{
*Correspondence: 298f@vghtc.gov.tw

${ }^{\dagger} Y$ Yu-Tsung Lin and Kuo-Chih Su contributed equally to this work.

${ }^{1}$ Department of Orthopedics, Taichung Veterans General Hospital, Taichung, Taiwan

Full list of author information is available at the end of the article
}

spondylolisthesis is instrumented spinal fusion with or without reduction. Although the superiority of clinical outcomes following instrumented fusion with reduction versus instrumented fusion in situ is highly debated [2-5], reduction of the spondylolisthesis may enhance the rate of fusion by increasing the bony contact and the area in compression, reducing the stress across the fusion mass [6]. According to a systemic review comparing fusion in situ with fusion after reduction, fusion after reduction was found to decrease slippage percentage and improve the fusion rate of spondylolisthesis [5]. original author(s) and the source, provide a link to the Creative Commons licence, and indicate if changes were made. The images or other third party material in this article are included in the article's Creative Commons licence, unless indicated otherwise in a credit line to the material. If material is not included in the article's Creative Commons licence and your intended use is not permitted by statutory regulation or exceeds the permitted use, you will need to obtain permission directly from the copyright holder. To view a copy of this licence, visit http://creativecommons.org/licenses/by/4.0/. The Creative Commons Public Domain Dedication waiver (http://creativeco mmons.org/publicdomain/zero/1.0/) applies to the data made available in this article, unless otherwise stated in a credit line to the data. 
Specifically, in patients with high-grade spondylolisthesis with abnormal posture, reduction and realignment procedures should be performed to restore the global spinopelvic balance $[5,7,8]$.

The most commonly used approach for spinal fusion is the posterior approach. The posterior approach can be used in instrumented interbody fusion techniques, such as posterior lumbar interbody fusion (PLIF) or transforaminal lumbar interbody fusion (TLIF), which leads to a satisfactory outcome in patients with spondylolisthesis [9]. The anterior approach of the lumbar spine, which can be used in instrumented interbody fusion technique of anterior interbody fusion (ALIF), can facilitate access to the intervertebral space without passing through the spinal canal with retraction of the nerve roots and cauda equina, reducing the potential risk of nerve injury and dural tear [10].

Several studies have compared the clinical outcomes of anterior and posterior spinal fusion as a treatment for lumbar spondylolisthesis. Tye et al. have compared ALIF and TLIF in patients with isthmic spondylolisthesis. Their results revealed that the functional score improved significantly for both groups 1 year after the operation. However, the EuroQol-5D (EQ-5D) scores improved significantly more in patients in the ALIF group than those in the TLIF group [11]. Besides, Min et al. have also found that in patients who underwent L4-L5 fusion surgery for spondylolisthesis, ALIF is more advantageous in preventing the development of adjacent segment disease (ASD) compared with PLIF [12].

Among the reduction techniques, the lever reduction technique through the anterior approach was first described by Bradford et al. [13]. In this procedure, the tip of a Hohmann retractor was positioned at the posterior rim of the upper endplate of the lower vertebrae, which was then used as a fulcrum to reduce the slippage of the spondylolisthesis. In contrast, Kong et al. [14] have also developed a lever reduction technique that can achieve reduction with a lever repositioner via the posterior approach.

Although the anterior spinal fusion appears to have several clinical advantages over posterior spinal fusion, previous biomechanical studies mostly focused on the stability and alignment changes of the spinal fusion structure after the procedure [15-18]. No studies have so far investigated behavior while performing the spondylolisthesis reduction and the difference between the anterior and posterior reduction techniques.

This study aimed to investigate the biomechanical behavior while performing reduction maneuvers of spondylolisthesis using the anterior and posterior lever reduction methods. This information can provide clinical physicians the basic mechanics of different reduction techniques in spondylolisthesis surgery.

\section{Methods \\ Establishment of spondylolisthesis model}

Twenty lumbar spine sawbone models (lumbar vertebrae, model 1352, Pacific Research Laboratories, Vashon, WA, USA) were used as experimental models to examine the effects of anterior lever and posterior lever reduction methods. The intervertebral disc and anterior and posterior longitudinal ligaments of L4-L5 segment were resected. The $\mathrm{L} 4$ vertebrae were positioned at the anterior third of the L5 vertebrae, which simulated Meyerding grade 3 spondylolistheses [19]. A customized clamp was subsequently used to set up the spine sawbone model on a mechanical testing system (MTS 858 Mini Bionix Testing Machine; MTS Systems Corp., Eden Prairie, MN) (Fig. 1).

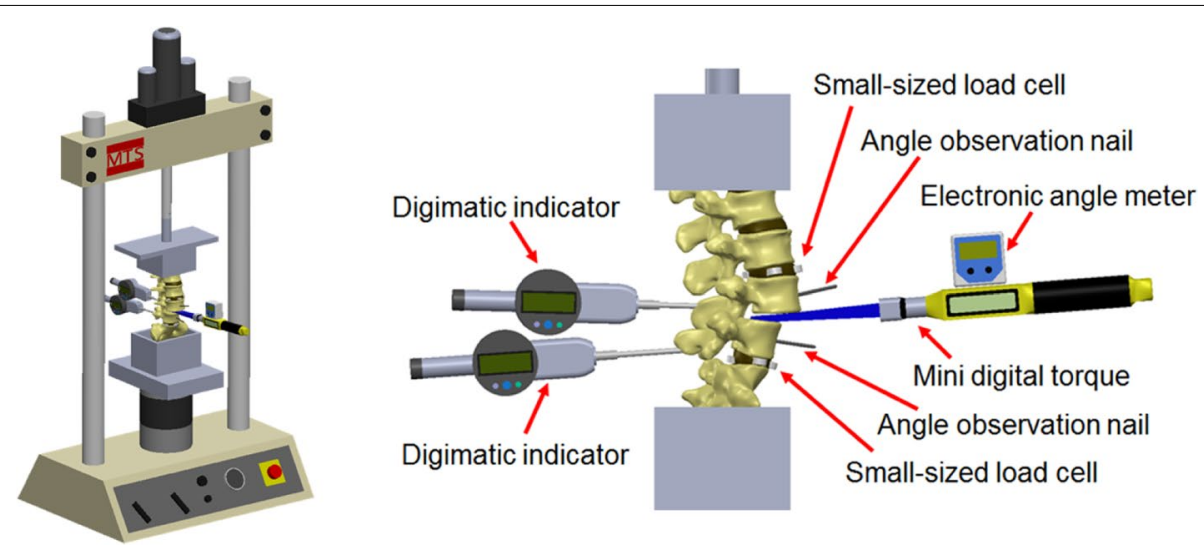

Fig. 1 The spondylolisthesis model was mounted on the mechanical testing system tensile testing machine. Mechanical instruments were set up to measure different parameters during spondylolisthesis reduction 


\section{Reduction procedure}

The procedures in the present study were performed by two experienced spine surgeons. Each of them performed 25 anterior lever reductions in five sawbones and 25 posterior lever reductions in another five sawbones. During anterior lever reduction, the surgeon applied a Cobb elevator to the intervertebral body space anteriorly. The tip of the Cobb was placed at the posterior rim of the L5 upper endplate, which served as a fulcrum (Fig. 2a). Subsequently, a force was applied to pry the slipped vertebrae until reduction was achieved based on the surgeon's judgment.

During posterior lever reduction, a Cobb elevator was applied through the interbody space either from the left or the right side. The tip of the Cobb was placed at the anterior rim of the L4 lower endplate, and the L5 vertebrae served as a lever fulcrum when performing lever reduction (Fig. 2b). Force was subsequently applied to pry the slipped vertebrae backward until reduction was achieved based on the surgeon's judgment.

\section{Setting of the mechanical testing system}

The spondylolisthesis model was set up on the MTS tensile testing machine. Mechanical instruments were used to measure the change in mechanics of the lumbar vertebrae during reduction (Fig. 1). An electronic angle meter and mini digital torque wrench were installed on the customized Cobb elevator to measure the angular motion and torque of the Cobb elevator while performing reduction maneuver. The electronic angle meter sensed the angular change of Cobb. The mini digital torque wrench (WM-106-1, Asmith Manufacturing Company, Taiwan) detected the torque, with the range of measurement between 30 and $600 \mathrm{~N}-\mathrm{cm}$.

To observe the movement of vertebral bodies during spondylolisthesis reduction, two digimatic indicators (Mitutoyo digimatic indicator, Type ID-C1050MXB, Mitutoyo Manufacturing Co. Ltd., Tokyo, Japan) were set up at the spinous processes of L4 and L5. The indicators were used to measure forward and backward displacement of the reduced vertebral body, with the range of measurement up to $50.8 \mathrm{~mm}$. Furthermore, two angle observation nails were inserted into the center of the anterior vertebral bodies of L4 and L5, which were used to measure the change of lordotic angle between the L4 and L5 vertebral bodies after performing the reduction.

The lumbar spine sawbone model was set up on the MTS machine (MTS 858 Mini Bionix) so that the cells in the MTS could measure both the total axial force and total torque applied on the model. These two forces represented the resultant force received by the entire lumbar spine while a surgeon performed the reduction.

To observe the force created over the adjacent intervertebral disc during spondylolisthesis reduction, eight small-sized compression load cells (LMB-A-2KN, Kyowa Electronic Instruments Co. Ltd., Tokyo) were used to measure the force distribution in intervertebral discs near L4 and L5. The maximum force that could be measured was $2 \mathrm{kN}$. Small-sized load cells were inserted at the anterior, posterior, left, and right positions of the intervertebral discs at the L3-L4 and L5-S1 segments. The cells inserted in L3-L4 were numbered 1-4, whereas those inserted into the L5-S1 intervertebral disc were numbered 5-8 (Fig. 3).

Differences between the measured data of the two methods were tested using Student's t-test. The statistical analysis was performed using Statistical Package for Social sciences version 22.0 (SPSS Inc., Armonk, NY). A $p$-value of $<0.05$ was considered statistically significant.

\section{Results}

Observation of the mini digital torque wrench on Cobb elevator revealed that anterior lever reduction led to significantly lesser torque on Cobb $(116 \mathrm{~N}-\mathrm{cm}$ vs. $155 \mathrm{~N}-\mathrm{cm}, p<0.001$, Table 1, Fig. 4a). Moreover, the electronic angle meter on Cobb elevator showed that (a)

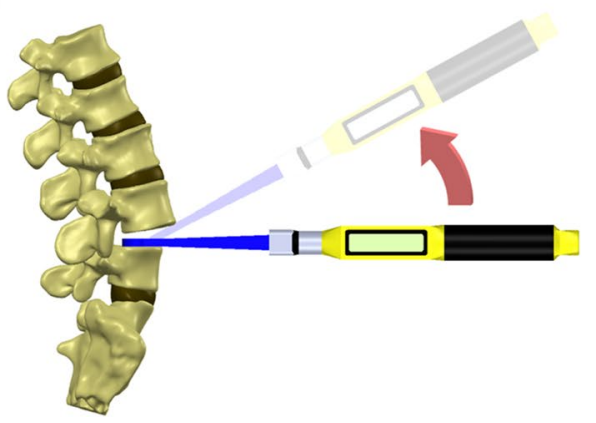

(b)

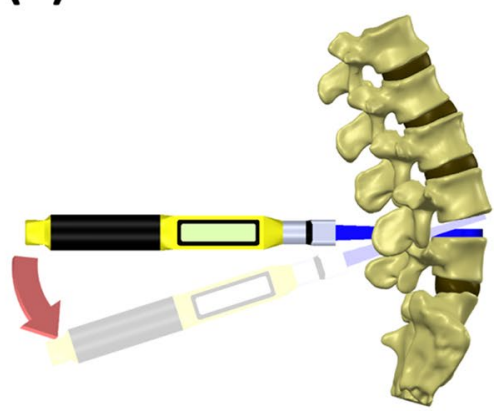

Fig. 2 Illustration of the reduction process. a anterior lever reduction; b posterior lever reduction 


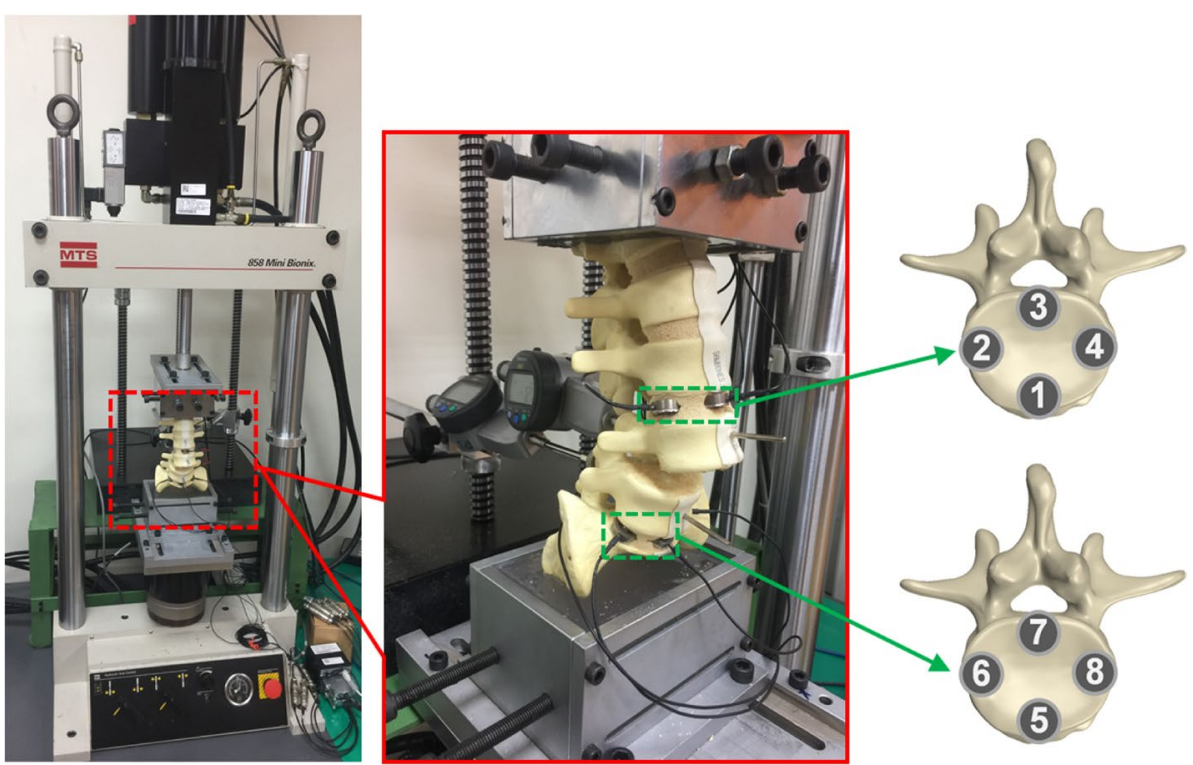

Fig. 3 Small-sized compression load cells were inserted at the adjacent intervertebral disc. No.1-No.4 load cells were placed at L3/4 intervertebral disc. No.5-8 load cells were placed at L5/S1 intervertebral disc. The model was then set up on the mechanical testing system machine

Table 1 Recorded parameters

\begin{tabular}{llll}
\hline & Anterior lever reduction & Posterior lever reduction & $\boldsymbol{p}$ Value \\
\hline Torque of Cobb $(\mathrm{N}-\mathrm{cm})$ & $116 \pm 7.7$ & $155 \pm 21$ & $<.001^{* *}$ \\
Angular motion of Cobb (degree) & $53.22 \pm 4.1$ & $37.96^{\circ} \pm 2$ & \\
Displacement of vertebral body $(\mathrm{mm})$ & & & $<.001^{* *}$ \\
$\quad \mathrm{~L}$ (backward displacement) & $7.35 \pm 1.52$ & $6.74 \pm 0.97$ & $0.02^{*}$ \\
$\quad \mathrm{~L}$ (forward displacement) & $1.57 \pm 0.25$ & $0.87 \pm 0.25$ & $<0.001^{* *}$ \\
Change of lordotic angle $(\Delta$ degree) & $-2.39 \pm 1.52$ & $-4.88 \pm 1.94$ & $<0.8 \pm 4.54$ \\
Total axial force of the model $(\mathrm{N})$ & $16.38 \pm 4.51$ & $12 \pm 5.1$ & $<0.001^{* *}$ \\
Total torque of the model $(\mathrm{N}-\mathrm{cm})$ & $9 \pm 3.9$ & $0.003^{* *}$ \\
\hline
\end{tabular}

Student's t-test, ${ }^{*} p<0.05,{ }^{* *} p<0.01 ;$ Mean values are presented \pm SD

anterior lever reduction had greater angular motion compared with posterior lever reduction $\left(53^{\circ}\right.$ vs. $38^{\circ}$, $p<0.001$, Table 1, Fig. 4b).

The digimatic indicators showed that L4 would undergo backward displacement after reduction (Table 1), whereas L5 would be displaced slightly forward. Displacement of L4 and L5 vertebral bodies were significantly higher in the anterior lever method than in the posterior (Table 1). The observation nails revealed that the posterior lever reduction decreased the lordotic angle more than the anterior lever reduction, gaining significant difference $\left(-2.4^{\circ}\right.$ and $-4.9^{\circ}$, $p<0.001$, Table 1).

Posterior lever reduction added a greater total axial force to the lumbar spine model $(40.8 \mathrm{~N}$ vs. $16.38 \mathrm{~N}$, $p<0.001$, Fig. 4c). Moreover, posterior lever reduction also resulted in greater torque to the model. However, the torque values were small in both methods $(12 \mathrm{~N}-\mathrm{cm}$ vs. $9 \mathrm{~N}-\mathrm{cm}, p=0.003$, Fig. $4 \mathrm{~d}$ ).

Among the four load cells at L3-L4 disc level (Table 2, Fig. 4e), cell no. 1, which was located at the anterior position of this level, experienced the highest force in both methods, which was higher in the anterior lever reduction compared with the posterior lever reduction method $(21.4 \mathrm{~N}$ vs. $14.78 \mathrm{~N}, p<0.001$, Table 2). Among the four cells at L5-S1 level (Table 2, Fig. 4f), cell no. 7, which was located at the posterior position at this level, experienced the highest force in both methods, which was higher in the posterior lever reduction compared with the anterior lever reduction $(31.54 \mathrm{~N}$ vs. $5.5 \mathrm{~N}, p<0.001$, Table 2$)$. 


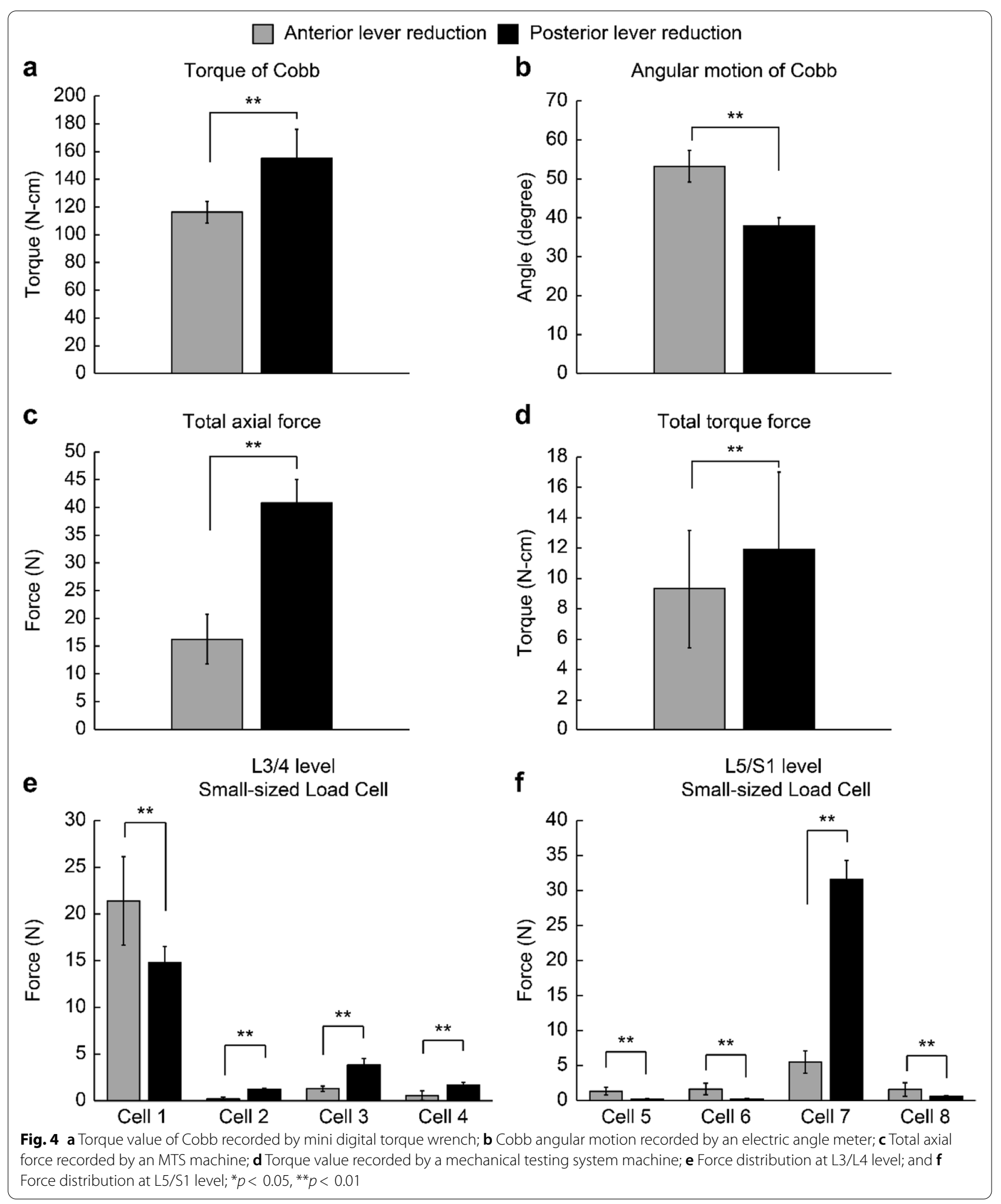


Table 2 Force recorded by small-sized load cell (N) at adjacent disc

\begin{tabular}{llll}
\hline Small-sized load cell & $\begin{array}{l}\text { Anterior lever } \\
\text { reduction }\end{array}$ & $\begin{array}{l}\text { Posterior lever } \\
\text { reduction }\end{array}$ & $\boldsymbol{p}$ Value \\
\hline $\begin{array}{l}\text { L3/L4 intervertebral level } \\
\text { Cell No. } 1\end{array}$ & $21.4 \pm 4.74$ & $14.78 \pm 1.74$ & $<0.001^{* *}$ \\
Cell No. 2 & $0.22 \pm 0.21$ & $1.24 \pm 0.11$ & $<0.001^{* *}$ \\
Cell No. 3 & $1.3 \pm 0.28$ & $3.82 \pm 0.71$ & $<0.001^{* *}$ \\
Cell No. 4 & $0.57 \pm 0.51$ & $1.69 \pm 0.28$ & $<0.001^{* *}$ \\
L5/S1 intervertebral level & & & \\
Cell No. 5 & $1.34 \pm 0.57$ & $0.16 \pm 0.12$ & $<0.001^{* *}$ \\
Cell No. 6 & $1.65 \pm 0.81$ & $0.23 \pm 0.1$ & $<0.001^{* *}$ \\
Cell No. 7 & $5.5 \pm 1.62$ & $31.54 \pm 2.75$ & $<0.001^{* *}$ \\
Cell No. 8 & $1.58 \pm 0.97$ & $0.6 \pm 0.13$ & $<0.001^{* *}$ \\
\hline
\end{tabular}

Student's t-test, ${ }^{*} p<0.05,{ }^{* *} p<0.01$; Mean values are presented \pm SD

\section{Discussion}

The reduction of spondylolisthesis plays an important role in enhancing fusion rate while preventing slippage progression after instrumented spinal fusion, especially in high-grade spondylolisthesis patients [5]. Clinically, in patients with low-grade spondylolisthesis, either anterior or posterior reduction followed by mono-segment instrumentation provides excellent fusion rate and satisfactory functional outcome $[9,20,21]$. Several studies have compared the outcome between anterior and posterior spinal fusion in this population. Tye et al. found that both ALIF and TLIF could significantly improve the functional score 1 year after the operation. However, ALIF reportedly results in significantly greater improvement in EQ-5D scores than TLIF [11]. Furthermore, Min et al. have also reported that ALIF is more advantageous in preventing the development of ASD compared with PLIF [12].

In patients with high-grade spondylolisthesis, the treatment of anterior reduction followed by single-level spinal fusion was first described by Bradford et al. [13]. Later, David et al. [22] found that single-level ALIF, followed by mono-segment posterior instrumentation, provides excellent outcomes in this patient population. All the patients included in their study had achieved bony fusion. Moreover, complete reduction of slippage had been observed in $87.5 \%$ of these patients at the 17 -month follow-up. Furthermore, in a preliminary report conducted by $\mathrm{Tu}$ et al., anterior cantilever reduction procedure followed by ALIF and posterior mono-segment instrumented fusion could achieve a high fusion rate while correcting lumbosacral angle [23]. On the contrary, Lengert et al. [24] found that patients who underwent posterior reduction with mono-segment posterior instrumentation experienced loss of reduction 1 year after the operation. Therefore, posterior L4-S1 fusion provided better outcomes than single-level L5-S1 fusion in patients with high-grade L5/S1 spondylolisthesis.

Our findings suggest that the anterior lever reduction method can achieve spondylolisthesis reduction in an effort-saving manner without adding excessive force over the entire lumbar spine. This result supports the existing evidence that the anterior lever reduction technique has a mechanical advantage over the posterior lever reduction technique, which might be one of the contributing factors to treat high-grade lumbar spondylolisthesis with short-segment instrumentation successfully.

From a mechanical viewpoint, the anterior lever reduction method involves a class 2 lever, whereas the posterior lever reduction method involves a class 1 lever. Because the length of the lever arm is greater (Fig. 5, $\mathrm{L}>\mathrm{L}-\mathrm{BCL}-(\mathrm{BL}) / 2)$, anterior lever reduction requires lesser force to achieve reduction than posterior lever reduction (Fig. 5, ARF < PRF), which finally leads to lesser torque on Cobb and lesser resultant force to the entire lumbar spine. Figure 5 presents the mechanical free body diagrams to analyze the force applied by the surgeon during lever reduction.

Anterior approach of the spine has become an effective and popular alternative for achieving lumbar fusion. The anterior and middle column provides $80 \%$ of the weight-bearing load of the spinal column, and the anterior approach offers efficient and direct access to this area [25]. In the present study, we found that the angular motion of Cobb during reduction was greater while performing the anterior lever reduction method compared with the posterior lever reduction method. This is because the anterior approach of the spine was not hindered by the complex structure of the posterior spine. Therefore, a surgeon can achieve reduction with Cobb through an ideal angle (Fig. 5, $\theta_{\mathrm{A}}>\theta_{\mathrm{P}}$ ).

The backward displacement of L4 and forward displacement of L5 vertebral bodies were both greater using the anterior lever method. This result suggested that anterior reduction can achieve a better degree of slip reduction by applying lesser force to the lumbar spine, proving that the anterior reduction is biomechanically more efficient than posterior reduction. Despite this advantage, in patient with high-grade spondylolisthesis, partial reduction may be safer than complete reduction. According to Bradford et al. [26], the risk of iatrogenic neurologic injury correlates with the degree of reduction obtained. In previous literature, partial reduction of high-grade spondylolisthesis seemed to provide a satisfactory outcome with a low incidence of nerve traction injury after the procedure [23]. Therefore, our results suggest that both methods can successfully achieve reduction. Meanwhile, the risk of nerve root stretch injury among both methods may be similar if the goal of slippage reduction is the same. 
(a)
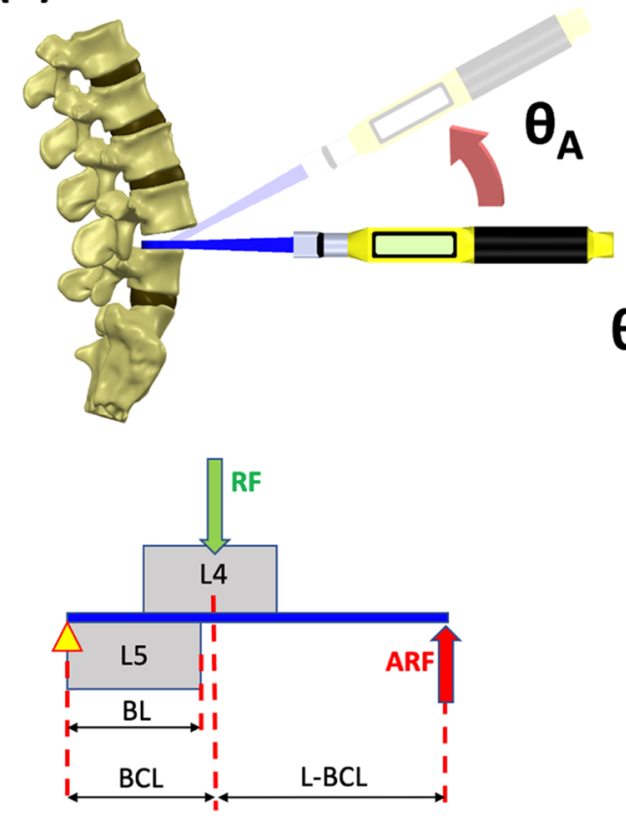

$R F \times B C L=A R F \times L$ (b)
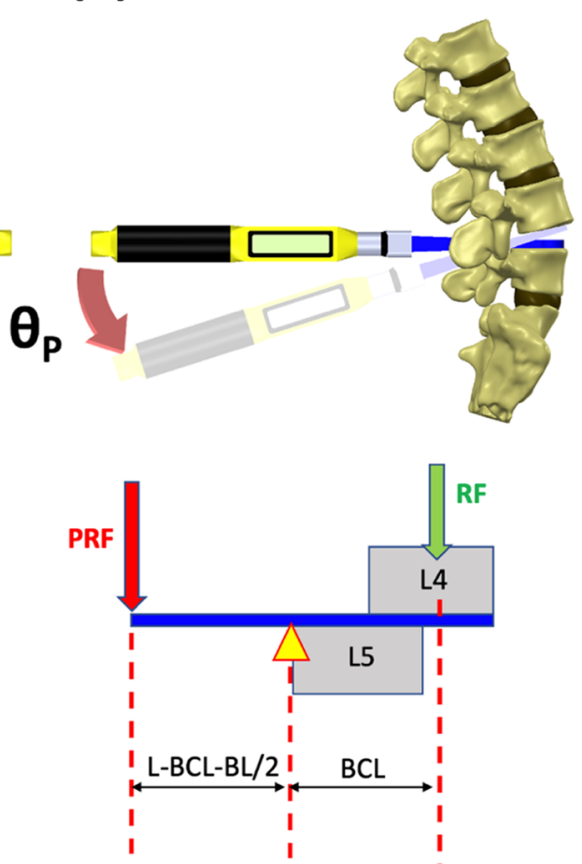

$\mathrm{RF} \times \mathrm{BCL}=\mathrm{PRF} \times\left(\mathrm{L}-\mathrm{BCL}-\frac{\mathrm{BL}}{2}\right)$

$P R F=\frac{R F X B C L}{L-B C L-\frac{B L}{2}}$

$$
\begin{gathered}
\because L>L-B C L-\frac{B L}{2} \\
\therefore A R F<P R F
\end{gathered}
$$

Fig. 5 Mechanical free body diagrams of both reduction methods. The lever arm of anterior lever reduction is greater than the posterior reduction method $(\mathrm{L}>\mathrm{L}-\mathrm{BCL}-(\mathrm{BL}) / 2)$; therefore, the force required to achieve reduction is lesser (ARF $<\mathrm{PRF}$ ). $\mathbf{a}$ Anterior lever reduction involves a class 2 lever; $\mathbf{b}$ Posterior lever reduction involves a class 1 lever. ARF, anterior reduction force; PRF, posterior reduction force; RF, resistance force; L: Cobb length; BL: body length; $B C L: ~ L 4$ body center length

Regardless of the reduction method, the reduction process will add pressure on the adjacent segments. The data from the small-sized load cells revealed that the anterior reduction method might increase pressure over the upper adjacent disc (Cell No.1 at L3/4 level). In contrast, the posterior reduction may increase pressure over the lower adjacent disc (Cell No.7 at L5/S1 level).

Our study has a few limitations. The L4-L5-S1 segments contribute to two-thirds of the lordotic angle of the lumbar spine. The intervertebral disc, anterior and posterior longitudinal ligaments were removed to establish a high-grade spondylolisthesis model. This created hyperlordosis of the lumbar spine due to vertebral body slippage without ligament constraint. However, a normal lordosis angle can be achieved after a reduction maneuver, which decreases lordotic angle in both methods. This is somewhat different from the clinical scenario [23]. Second, stretching and subsequent straining of the nerve root can cause iatrogenic neurologic injury during spondylolisthesis reduction, which should be monitored during the operation. However, this could not be simulated in our model. Third, although the segment most commonly affected by degenerative spondylolisthesis is L4-L5, most cases of spondylolisthesis occur at L5-S1. However, the spondylolisthesis model simulated in this study was set at L4-L5 because of the difficulty in setting mechanical instruments at the L5-S1 segment in a sawbone model. Finally, although the force over the adjacent disc was observed in the spondylolisthesis model, the force applied over vertebral endplates was not measured, which may be important, especially in osteoporosis patients because of the vulnerability of endplate that can be violated during the reduction procedure.

Although the models used in the present study differed relatively from the clinical situation, the trends of biomechanical results remained similar. We also 
established a new lumbar spine mechanical measurement system by employing an MTS machine to collect more data than previous experiments.

\section{Conclusions}

The anterior lever reduction is a more effort-saving method than the posterior lever reduction method. The existing evidence supports the biomechanical advantage of the anterior reduction method, which might be one of the contributing factors to successfully treating high-grade lumbar spondylolisthesis with short-segment instrumentation.

\section{Abbreviations}

ALIF: Anterior lumbar interbody fusion; ASD: Adjacent segment disease; MTS: Mechanical testing system; PLIF: Posterior lumbar interbody fusion; TLIF: Transforaminal lumbar interbody.

\section{Acknowledgments}

We would like to thank Taichung Veterans General Hospital (TCVGH-1055103B and TCVGH-1075106C) in Taiwan for providing the funding for this research and the 3D Printing Research and Development Group of Taichung Veterans General Hospital for helping us to draw the pictures. The authors Yu-Tsung Lin and Kuo-Chih Su contributed equally to this work.

\section{Authors' contributions}

Conception and design; CH Lee and KC Su, Methodology; CH Lee, YT Lin and KC Su, Data curation; KH Chen, CC Pan and CM Shih, Writing; YT Lin and KC Su. All authors reviewed the manuscript. The author(s) read and approved the final manuscript.

\section{Funding}

Not applicable.

\section{Availability of data and materials}

Data and materials are available from the corresponding author under at a reasonable request.

\section{Declarations}

\section{Consent to publication}

Not applicable.

\section{Ethics approval and consent to participate}

The article does not involve any studies with human participants or animals.

\section{Competing interests}

The authors declare that they have no competing interests.

\footnotetext{
Author details

1 Department of Orthopedics, Taichung Veterans General Hospital, Taichung, Taiwan. ${ }^{2}$ Department of Medical Research, Taichung Veterans General Hospital, Taichung, Taiwan. ${ }^{3}$ Department of Biomedical Engineering, Hungkuang University, Taichung, Taiwan. ${ }^{4}$ Department of Chemical and Materials Engineering, Tunghai University, Taichung, Taiwan. ${ }^{5}$ Department of Computer Science and Information Engineering, Providence University, Taichung, Taiwan. ${ }^{6}$ National Chung Hsing University, Taichung, Taiwan. ${ }^{7}$ Department of Rehabilitation Science, Jenteh Junior College of Medicine, Nursing, and Management, Miaoli County, Taiwan. ${ }^{8}$ Department of Physical Therapy, Hungkuang University, Taichung, Taiwan. ${ }^{9}$ Department of Food Science and Technology, Hung Kuang University, Taichung, Taiwan.
}

Received: 22 April 2021 Accepted: 4 October 2021

Published online: 14 October 2021

\section{References}

1. Weinstein JN, Lurie JD, Tosteson TD, Zhao W, Blood EA, Tosteson AN, et al. Surgical compared with nonoperative treatment for lumbar degenerative spondylolisthesis. Four-year results in the spine patient outcomes research trial (SPORT) randomized and observational cohorts. J Bone Joint Surg Am. 2009:91:1295-304.

2. Poussa M, Remes V, Lamberg T, Tervahartiala P, Schlenzka D, Yrjönen $T$, et al. Treatment of severe spondylolisthesis in adolescence with reduction or fusion in situ: long-term clinical, radiologic, and functional outcome. Spine. 2006;31:583-90.

3. Transfeldt EE, Mehbod AA. Evidence-based medicine analysis of isthmic spondylolisthesis treatment including reduction versus fusion in situ for high-grade slips. Spine. 2007;32:S126-9.

4. Lian XF, Hou TS, Xu JG, Zeng BF, Zhao J, Liu XK, et al. Single segment of posterior lumbar interbody fusion for adult isthmic spondylolisthesis: reduction or fusion in situ. Eur Spine J. 2014;23:172-9.

5. Longo UG, Loppini M, Romeo G, Maffulli N, Denaro V. Evidence-based surgical management of spondylolisthesis: reduction or arthrodesis in situ. J Bone Joint Surg Am. 2014;96:53-8.

6. Lamartina C, Zavatsky JM, Petruzzi M, Specchia N. Novel concepts in the evaluation and treatment of high-dysplastic spondylolisthesis. Eur Spine J. 2009;18(Suppl 1):133-42.

7. Labelle H, Mac-Thiong JM, Roussouly P. Spino-pelvic sagittal balance of spondylolisthesis: a review and classification. Eur Spine J. 2011;20(Suppl 5):641-6.

8. Kunze KN, Lilly DT, Khan JM, Louie PK, Ferguson J, Basques BA, et al. Highgrade spondylolisthesis in adults: current concepts in evaluation and management. Int J Spine Surg. 2020;14:327-40.

9. Yan DL, Pei FX, Li J, Soo CL. Comparative study of PILF and TLIF treatment in adult degenerative spondylolisthesis. Eur Spine J. 2008;17:1311-6.

10. Mobbs RJ, Phan K, Malham G, Seex K, Rao PJ. Lumbar interbody fusion: techniques, indications and comparison of interbody fusion options including PLIF, TLIF, MI-TLIF, OLIF/ATP, LLIF and ALIF. J Spine Surg. 2015;1:2-18.

11. Tye EY, Tanenbaum JE, Alonso AS, Xiao R, Steinmetz MP, Mroz TE, et al. Circumferential fusion: a comparative analysis between anterior lumbar interbody fusion with posterior pedicle screw fixation and transforaminal lumbar interbody fusion for L5-S1 isthmic spondylolisthesis. Spine J. 2018;18:464-71.

12. Min J-H, Jang J-S, Lee S-H. Comparison of anterior-and posteriorapproach instrumented lumbar interbody fusion for spondylolisthesis. J Neurosurg Spine. 2007;7:21-6.

13. Bradford DS. Treatment of severe spondylolisthesis. A combined approach for reduction and stabilization. Spine. 1979;4:423-9.

14. Kong C, Wang W, Li X, Sun X, Ding J, Lu S. A new lever reduction technique for the surgical treatment of elderly patients with lumbar degenerative spondylolisthesis. BMC Musculoskelet Disord. 2020;21:11.

15. Fogel GR, Turner AW, Dooley ZA, Cornwall GB. Biomechanical stability of lateral interbody implants and supplemental fixation in a cadaveric degenerative spondylolisthesis model. Spine. 2014;39:E1138-46.

16. Hitchon PW, Mahoney JM, Harris JA, Hussain MM, Klocke NF, Hao JC, et al. Biomechanical evaluation of traditional posterior versus anterior spondylolisthesis reduction in a cadaveric grade I slip model. J Neurosurg Spine. 2019:31.2:246-54.

17. Wang W, Aubin CE, Cahill P, Baran G, Arnoux PJ, Parent S, et al. Biomechanics of high-grade spondylolisthesis with and without reduction. Med Biol Eng Comput. 2016;54:619-28.

18. Hsieh YY, Tsuang FY, Kuo YJ, Chen CH, Chiang CJ, Lin CL. Biomechanical analysis of single-level interbody fusion with different internal fixation rod materials: a finite element analysis. BMC Musculoskelet Disord. 2020;21:100.

19. Meyerding H. Spondylolisthesis. Surg Gynecol Obstet. 1932;54:371-7.

20. Ishihara H, Osada R, Kanamori M, Kawaguchi Y, Ohmori K, Kimura T, et al. Minimum 10-year follow-up study of anterior lumbar interbody fusion for isthmic spondylolisthesis. J Spinal Disord. 2001;14:91-9. 
21. Riouallon G, Lachaniette CH, Poignard A, Allain J. Outcomes of anterior lumbar interbody fusion in low-grade isthmic spondylolisthesis in adults: a continuous series of 65 cases with an average follow-up of 6.6 years. Orthop Traumatol Surg Res. 2013;99:155-61.

22. Xu DS, Bach K, Uribe JS. Minimally invasive anterior and lateral transpsoas approaches for closed reduction of grade II spondylolisthesis: initial clinical and radiographic experience. Neurosurg Focus. 2018;44:E4.

23. Tu KC, Shih CM, Chen KH, Pan CC, Jiang FC, Hsu CE, et al. Direct reduction of high-grade lumbosacral spondylolisthesis with anterior cantilever technique-surgical technique note and preliminary results. BMC Musculoskelet Disord. 2021;22(1):1-10.

24. Lengert R, Charles YP, Walter A, Schuller S, Godet J, Steib JP. Posterior surgery in high-grade spondylolisthesis. Orthop Traumatol Surg Res. 2014;100:481-4.
25. Mummaneni PV, Haid RW, Rodts GE. Lumbar interbody fusion: state-ofthe-art technical advances: invited submission from the joint section meeting on disorders of the spine and peripheral nerves, march 2004. J Neurosurg Spine. 2004;1:24-30.

26. Bradford DS, Boachie-Adjei O. Treatment of severe spondylolisthesis by anterior and posterior reduction and stabilization. A long-term follow-up study. J Bone Joint Surg Am. 1990;72:1060-6.

\section{Publisher's Note}

Springer Nature remains neutral with regard to jurisdictional claims in published maps and institutional affiliations.
Ready to submit your research? Choose BMC and benefit from:

- fast, convenient online submission

- thorough peer review by experienced researchers in your field

- rapid publication on acceptance

- support for research data, including large and complex data types

- gold Open Access which fosters wider collaboration and increased citations

- maximum visibility for your research: over $100 \mathrm{M}$ website views per year

At BMC, research is always in progress.

Learn more biomedcentral.com/submissions 